\title{
Marcados en la piel: vacunación y viruela en Argentina (1870-1910)
}

\author{
Marked on the skin: vaccination and smallpox in Argentina
} (1870-1910)

\begin{abstract}
This paper studies the smallpox vaccination in Argentina since 1870, when these discussions were inittiaded until the 1910s, when they were extended to the rest of the country. We analyze immunization practices implemented prior to the compulsory vaccination law, passed in 1886 for the Capital and in 1904 for the rest of the country. Such a move found resistance from different sectors. Its approval depended on the consequences of modernization and urbanization, the weight of hygienists in the political arena, and its extension depended on a different administrative conception, incorporating new areas and sectors to the national scenario.
\end{abstract}

Key words Mandatory vaccination, Smallpox, Argentina, Hygienism
Resumen Este artículo estudia la vacunación antivariólica en Argentina desde 1870, cuando se inician los debates al respecto, hasta la década de 1910, cuando se amplía al resto del país. Se analizan las prácticas de inmunización puestas en marcha con anterioridad a la Ley de vacunación obligatoria, aprobada en 1886 para la Capital y en 1904 para el resto del país. Tal medida fue resistida desde diferentes sectores. Su aprobación dependió de las consecuencias del proceso de modernización y urbanización acelerada, del peso de los higienistas en el escenario político y su extensión dependió de una concepción administrativa diferente, que incorporaba nuevas áreas y sectores al escenario nacional.

Palabras clave Vacunación obligatoria, Viruela, Argentina, Higienismo

${ }^{1}$ Facultad de Ciencias Humanas, Universidad Nacional de La Pampa. Gil 353, Santa Rosa, La Pampa, 6300, Argentina. silviadiliscia@gmail.com 


\section{Introducción}

La viruela, decía el Director del Departamento Nacional de Higiene, José Penna, era la enfermedad vergonzante de América [...] que determinaba manifestaciones epidémicas frecuentes y casi periódicas, durante las cuales, parodiando el refrán del recuerdo de Santa Bárbara, cuando truena, las gentes venían recién a pensar que existe una vacuna inmunizante ${ }^{1}$. Y reafirmaba su mentor, José María Ramos Mejía: Como la gota de agua tenaz que al fin horada la piedra concluirá por despoblar nuestras campañas y ciudades, si su carácter habitualmente maligno no se atenúa con la vacuna, o por marcarnos a todos con las terribles maculaciones que desfiguran el rostro de los que olvidan el precepto elemental e ineludible de vacunarse al menos una vez en la vida ${ }^{2}$.

Adelantarse y prevenir el azote de ésta y otras graves enfermedades fue uno de los principales fines de una generación de higienistas, quienes justificaban una mayor intervención sobre los cuerpos para aislar, limpiar, ordenar y vacunar. Según la definición más usual, la medicalización constituye un proceso llevado a cabo desde el Estado para modificar las normas y valores individuales, atendiendo al bienestar colectivo y futuro para tales imposiciones. Pero tal proyecto no debe evaluarse a la manera de la historiografía tradicional, como fruto del avance y del progreso científico, ni tampoco desde el punto de vista del control automático y restrictivo del individuo a partir del biopoder sobre los cuerpos. Tal y como ha señalado Porter ${ }^{3}$, se debe atender a las especificidades que implican a los actores y al escenario del drama en particular.

Desde hace algún tiempo hemos planteado que la vacunación antivariólica constituye uno de los primeros y mejores ejemplos para observar tal situación, sobre todo en un territorio como la República Argentina de finales del siglo XIX y principios del XX, tanto sea para incluir grupos afines con los que se deseaba aumentar el nivel de contacto como para contribuir, negando la vacunación, a su extinción ${ }^{4}$.

¿Cómo era, en realidad este país que se definía a sí mismo blanco, europeo y quería asemejarse a los más desarrollados del globo? Se trataba de un inmenso espacio con una ecología y climas muy diversos; escasamente habitado por una población heterogénea, formada por nativos, criollos americanos y recientes inmigrantes europeos, la mayoría analfabeta; un territorio dividido por los intereses regionales y donde la Iglesia católica asumía un gran peso ideológico.
En resumen, una sociedad multicultural y un territorio poco cohesionado conspiraban contra la imposición de las élites argentinas para unificarlo e integrarlo al sistema capitalista mundial y al progreso cultural y social. La higiene constituyó uno de los imperativos de esa modernidad periférica ya que, al mismo tiempo que aseguraba la salud, podía suministrar también mano de obra obediente y disciplinada.

El análisis de la vacunación antivariólica funcionaría entonces como un pretexto para prestar atención a fenómenos no necesariamente médicos sino sociales y políticos en una etapa de profundos cambios en la sociedad argentina, porque estas políticas de inmunización supusieron un debate en relación a la legitimidad de la intervención pública sobre el cuerpo y las decisiones individuales. La organización de la vacunación fue un desafío para la organización sanitaria decimonónica y más adelante, la llegada de los vacunadores a sitios donde el Estado no tenía casi anclaje institucional le proporcionó al sistema público mayor visibilidad y a la vez información sobre territorios y habitantes totalmente desconocidos.

La historiografía más reciente sobre la salud y la enfermedad ha prestado escasa atención a esta problemática; salvo en cuestiones que vinculan la vacunación o inoculación con la necesidad de alianzas y/o el exterminio de grupos indígenas $^{5}$, los registros de las diferentes epidemias durante el XIX en Buenos Aires ${ }^{6}$ o bien para señalar el impacto de políticas sanitarias en la segunda mitad del siglo XX en la prensa contemporánea en la misma ciudad ${ }^{7}$. Sin embargo, se trata de una temática de gran interés en otras áreas, como puede registrarse en sólo algunos ejemplos examinados en América Latina ${ }^{8}$.

En relación a la resistencia a la inmunización, tomamos como base el estudio de Anne Marie Moulin, quien señala que es preciso observar la vacunación como una estrategia por la cual los poderes públicos encontraron la posibilidad de otorgar un cierto orden en los cuerpos y así por lo tanto, su oposición no sería necesariamente un anacronismo en la era del progreso. De esta manera, Es una reacción a un procedimiento médico aplicado por diferentes categorías de actores para alcanzar sus objetivos: el prestigio de la corporación médica, el control administrativo y sanitario de poblaciones fluctuantes. Es también una respuesta a un procedimiento médico que puede ser erróneo, validado de manera incompleta, aplicado inoportunamente o sin explicación ${ }^{9}$. Esta particularidad le imprime entonces una lógica cada vez que ha sido utilizada como metodolo- 
gía de reacción que en el caso argentino merece una mayor profundización.

La viruela, peligrosa enfermedad hoy desaparecida, se presentó de forma epidémica en el territorio nacional desde la llegada de los primeros europeos en el siglo XVI, pero no fue hasta principios del siglo XIX que se expandió la inoculación y variolización, al menos en las principales ciudades del entonces Virreinato del Río de La Plata. Así y todo, las epidemias se repitieron durante décadas, dejando su tendal de muertos o de convalecientes con graves consecuencias, como la ceguera y las marcas que desfiguraban para siempre la piel del rostro y el cuerpo. En 1949, el Manual escrito por los médicos González y Floriani señalaba que Todos los recursos de la propaganda de la educación y la convicción serán pocos para llevar la necesidad de vacunarse, la compenetración de la gravedad de la viruela y la seguridad de que la viruela existe por culpa de quienes no se vacunan $^{10}$. Tal situación implica entonces una revisión más profunda de alguna de las causas que limitaron la extensión de una medida publicitadamente como benéfica, partiendo de las etapas previas de la sanción de la legislación que propuso la obligatoriedad.

En este artículo, el objetivo es un examen profundo de la vacunación antivariólica en Argentina desde los primeros intentos para otorgarle una difusión general en los años de 1870 en las ciudades y pueblos del Litoral, hasta la década de 1910, cuando se amplía al resto del país. Las fuentes examinadas son la prensa científica contemporánea de asociaciones médicas, manuales y textos de reconocidos higienistas y documentación emanada de las principales agencias públicas, como la Asistencia Pública y el Departamento Nacional de Higiene.

Se analizan en primer lugar las prácticas de inmunización que se pusieron en marcha con anterioridad a la Ley de obligatoriedad de vacunación, focalizando en los diversos sectores opuestos a la medida. En la literatura tradicional, variolización y vacunación se visualizan teñidas con el éxito y en un camino ascendente que lleva a la sociedad toda a reconocer las ventajas y a hacerlas propias de forma natural. Un examen crítico del proceso lleva a conclusiones muy distintas y menos halagüeñas, porque la generalización de la vacuna a toda la población argentina fue una medida resistida desde ámbitos disímiles ya que se opusieron tanto la población de sectores populares como los médicos, académicos y las autoridades eclesiásticas. La obligatoriedad fue aprobada en 1886 en la Capital y en 1904 en el resto del país y si bien constituye un hecho importante, no es el único que explica la extensión de la medida, dado que la resistencia continuó con posterioridad, pero sí es útil para observarlo como uno de los principales elementos para la organización médico-sanitaria inicial, a partir del peso de los higienistas en el escenario político.

En segundo lugar, se consideran las estrategias utilizadas por las agencias públicas para la distribución de los virus atenuados a partir de campañas generales en el interior del país. En las ciudades principales, sobre todo en Buenos Aires, el avance de la intervención higiénica pública ya fuese en instituciones hospitalarias públicas, privadas o través del sistema educativo, incidió en la limitación de las epidemias. Tal situación es marcadamente diferente en los "nuevos espacios" (como se denominó a los Territorios Nacionales), donde fue muy lento el impulso estatal y la vacunación parece haber sido una medida central para asegurar la soberanía de la nación y la supervivencia de la población.

\section{Las primeras inoculaciones}

La inoculación, práctica popular en Asia Menor y Grecia, se introdujo en Europa a principios del siglo XVIII y de allí pasó a distintos lugares de América. Se realizaba a partir de la implantación en niños y adultos de costras de personas que hubiesen tenido la "viruela benigna". A finales del siglo XVIII, las investigaciones de Jenner en Gran Bretaña llevaron al uso de la variolización, es decir a la implantación artificial del virus de la viruela vacuna o cow pox, que tuvo una gran expansión en otras partes de Europa. La variolización ha sido definida como el primer gran éxito de la medicina de la Ilustración. De acuerdo a Lanning, la Corona española tuvo especial interés en hacer conocer dicho sistema a través de la Expedición de Francisco Balmis entre 1803 y 1807 a las colonias americanas, que llevaba niños con virus atenuado para vacunar a la población ${ }^{11}$.

Una de las primeras medidas del gobierno independiente formado en Buenos Aires en 1810 introdujo la lucha contra la viruela pero las urgencias político-militares debieron posponer los ímpetus revolucionarios. En 1813, La Gaceta de Buenos Aires publicó un Reglamento del clérigomédico Saturnino Segurola para prevenir a los habitantes de las Provincias Unidas - primera denominación de lo que luego será la Argentina - de los estragos de la viruela, por medio de la propagación del fluido vacuno. Se habilitaron al 
respecto en Buenos Aires casas de vacuna y empleados que inocularían a la población ${ }^{12}$.

La distribución de la vacuna continuó siendo un problema para las autoridades durante los siguientes veinte años, ya que se requería un registro concienzudo de la población, una organización estable que permitiera el acceso al material inmunológico (costras conservadas de variolosos o bien personas con costras para vacunar "brazo a brazo") y recursos económicos para mantener este incipiente servicio médico estatal. Se insistía una y otra vez sobre las ventajas de la variolización lo cual indica que muchos, tanto en las ciudades como en las áreas rurales, consideraban vacunarse como una desventaja y a los reparos de la población se sumaban a los inconvenientes de orden político-burocrático.

Entre 1821 y 1827, durante el gobierno de Martín Rodríguez y gracias al impulso de Bernardino Rivadavia, la vacunación fue un asunto central dentro de la creación y reorganización institucional sanitaria ${ }^{13}$, formalizándose una "comisión para la vacuna” que debía administrarla, generalizarla y conservarla. Rivadavia, siendo ministro de Martín Rodríguez, había creado la Academia y la Facultad de Medicina, el Tribunal de Medicina en reemplazo del Protomedicato, reglamentó la tarea de los médicos de campaña, de ejército, hospitales y de puerto, reorganizó el cuerpo de medicina del ejército y estableció la Sociedad de Beneficencia, que entre sus múltiples tareas debía atender el hospital de mujeres y la Casa de partos.

Asimismo, durante su gestión se reglamentó su distribución en la campaña bonaerense, invitándose a los distintos gobiernos de provincia a establecer oficinas de vacunación en sus jurisdicciones respectivas. Pero muy poco se avanzó en la inmunización general de la población, dada la casi inexistencia de un sistema público y las carencias financieras de un país atravesado por conflictos internos y externos e incluso, fue muy difícil lograr conservar el virus a partir del ganado.

En 1822, se formó en Buenos Aires un Consejo de Higiene bajo el impulso de uno de los principales reformadores de entonces, Bernardino Rivadavia. Dicha institución heredó las funciones del antiguo Protomedicato, formado en la época colonial. Este Consejo continuó durante el gobierno de Juan Manuel de Rosas para la administración de la sanidad e higiene con una injerencia provincial y tal como sus homónimos de las provincias del Norte, Litoral y Cuyo, estaba formado por facultativos, - miembros de una reducida élite -, quienes se encargaban de tareas como la higiene urbana y la regulación profesional de toda la rama médica y farmacéutica. En 1829 , luego de los intentos por lograr la unificación, se produjo un estallido de la organización nacional con la estructuración de estados provinciales que se mantuvieron en cierta autonomía hasta 1852 . Durante este período, se mantuvo la vacunación de la población en la ciudad y en las localidades del interior bonaerense, aunque es preciso realizar algunas precisiones.

Rosas obtuvo el apoyo de grupos populares (asociaciones de africanos, mujeres, artesanos y paisanos pobres, gauchos y montoneros), tanto en la ciudad como en la campaña bonaerense, donde llevó a cabo una política de amistad con determinados grupos indígenas. En 1830, cuando se declaró en Buenos Aires una epidemia de viruela que afectó sobre todo a los indios denominados "pampas" que estaban en la ciudad, el gobernador los visitó sin alarmarse ante el contagio. Mostró a los caciques que él también había sido vacunado y estimuló que hiciesen lo mismo, obteniendo a cambio una rendida admiración de los indígenas ante su valentía. Como desarrollé en otro trabajo, según el testimonio del viajero inglés W. Parish, más de cien indios aceptaron inmunizarse, por lo que esta práctica puede ser observada formando parte de los acuerdos y pactos realizados por el gobernador para pacificar el territorio ${ }^{14}$.

Paralelamente Francisco X. Muñiz, médico de campaña, iniciaba las investigaciones con las que logró el re-descubrimiento del cow-pox. En 1842 envió una nota a John Epps, director de la Real Sociedad Jenneriana de Londres, donde aseguraba con diferentes experiencias veterinarias realizadas durante largos años que se trataba de viruela vacuna y no de otra enfermedad del ganado, por lo que podían obtenerse de manera sencilla costras para vacunar a la población ${ }^{15}$. La Sociedad Jenneriana le agradeció sus servicios, aceptando en general los argumentos del investigador sobre la "vacuna indígena" y en 1844 el Tribunal de Medicina de Buenos Aires aceptó las vejiguillas obtenidas de vacunos nativos. Muñiz dio más ímpetu a esta medida al permitir que se inoculara a otros con el virus de su hija de meses.

Los relatos anteriores representan aspectos aislados ya que a mediados del siglo XIX se estaba muy lejos de considerar a esta práctica como habitual; las epidemias de viruela siguieron dejando cientos de víctimas, sobre todo entre las sociedades indígenas dueñas de toda la Patagonia, la Pampa, el Chaco y las actuales provincias de Formosa y Misiones, dado que la población carecía de mecanismos naturales de inmunización. 
Hacia 1853, la sanción de una Constitución significó el inicio de una nueva etapa en la cual se gestaría un proyecto nacional, aunque en la por entonces Confederación - otra denominación del actual territorio argentino - estuvo ausente la provincia de Buenos Aires. Hubo muy pocos cambios en relación a nuestro tema de estudio, ya que continuaron durante al menos dos décadas similares problemas en relación con la distribución de la vacuna y la resistencia a la vacunación por diversas razones (logísticas, políticas, económicas e ideológicas).

Las transformaciones comenzaron a producirse a raíz del impacto de las epidemias y de una mayor influencia de los médicos higienistas en el escenario primero porteño y luego, en el resto del país. El debate implicó a dos posturas, que fluctuaban entre la libertad de curar o el control médico. Para las autoridades, se trataba de un delicado problema ya que cada posibilidad implicaba considerar de diferente forma la ciudadanía, su educación y capacidad de elección. La cuestión era entonces si el pueblo estaba preparado para optar por sí mismo cómo obtener salud y bienestar, o si se trataba de una elección que debían hacer otros - la minoría culta -, en virtud de que la mayoría era ignorante, carecía de suficiente información y podía ser captada por prácticas dañinas.

A partir de 1852, con la caída de Rosas, el grupo triunfante asumió la enorme tarea de organizar legalmente el país. La mayoría eran liberales, pero al finalizar la larga lucha contra el grupo federal reconocían que el problema fundamental del país era no sólo dar legitimidad sino establecer en la Argentina un orden republicano que asegurara estabilidad política. El sistema democrático debía permitir derechos políticos para toda la población (entendida ésta como el conjunto de varones nativos y mayores de edad), pero el riesgo era que acabara bajo una dictadura populista o bajo la anarquía política. Así, se optó por dar forma a una "república posible", en camino hacia una "república verdadera". La discusión esencial era la unificación del ideal democrático con la representación ciudadana, resolución que tomó forma bajo un sistema que se ha denominado de sufragio universal y a la vez de voto restringido, con elecciones en ocasiones fraudulentas y limitada cantidad de ciudadanos.

Entre los años 1862-1880, durante las presidencias de Bartolomé Mitre, Domingo F. Sarmiento y Nicolás Avellaneda, se produjeron importantes transformaciones políticas y económicas en el país. La constitución de la unidad nacio- nal bajo Mitre fue el inicio de distintos mecanismos necesarios para el funcionamiento de la administración, como los servicios de comunicación (correo, ferrocarriles, telégrafo), la Aduana, el Banco Nación y la organización de un sistema legislativo y judicial, cuyo mejor ejemplo fue la promulgación del Código Civil y Comercial.

De acuerdo a Oszlak, la formación del Estado argentino implicó imponer socialmente una capacidad externa de poder, institucionalizando la autoridad a partir de medidas de coerción. A la vez, se diferenciaba el control estatal a través de instituciones públicas de reconocida legitimidad, que debían internalizar una identidad colectiva. La "estatidad" o presencia del Estado puede advertirse a través de la modalidad represiva (Ejército nacional); cooptativa, en la medida en que se realizaron alianzas entre diversos sectores dominantes del interior y la capital; ideológica, con la difusión de valores nacionales y por último material, cuando el avance del Estado se manifestó en obras de infraestructura y servicios públicos ${ }^{16}$.

En esa época plena de modificaciones se produjo también un debate sobre las políticas sanitarias estatales, relacionado con la disposición de los saberes en la formación del Estado. Este proceso se inició a partir de una situación crítica: el aumento de la mortalidad epidémica.

Las enfermedades contagiosas pusieron bajo la lupa la necesidad de generar mejoras en la infraestructura urbana y reducir la mortalidad, introduciendo a los médicos con mayor legitimidad para regular la vida y las costumbres de la población urbana. El cólera en 1868 y 1886 y la fiebre amarilla en 1871, con miles de muertos en el Litoral, constituyeron un verdadero "parteaguas” histórico. Según Diego Armus, abrieron la puerta a un sector de profesionales que requería para consolidarse de una mayor implicación en el Estado-nación, sentaron las bases discursivas sobre la peligrosidad del contagio infeccioso y sobre todo, hicieron sentir la indispensable regulación pública, haciendo de las enfermedades un problema social ${ }^{17}$. Esta situación se vincula con las transformaciones científico-médicas producto de la "Revolución Pastoriana" y con el estudio de microorganismos identificados como productores de patologías.

En el caso de la viruela, si bien era una enfermedad endémica en el Río de la Plata mucho tiempo antes, el número de víctimas aumentó significativamente en las áreas urbanas y rurales en la segunda mitad del XIX. Entre 1855-57, hubo 25 decesos por esta causa en la ciudad de Buenos Aires y 35 en la campaña; entre 1858-1867, ascen- 
dieron a 666 en la ciudad y a 1.728 en la campaña y en el decenio 1868-1877, a 4.796 y 9.875 respectivamente. Los picos epidémicos con miles de afectados y una alta mortalidad se produjeron en 1871,1875 y $1876^{18}$.

Tal situación debe verse en paralelo con las modificaciones demográficas y su impacto urbano. De acuerdo a Lobato y Suriano, en 1869 había en el país 1.830.214 habitantes, concentrados sobre todo en la región pampeana y metropolitana, aunque el Noroeste seguía siendo aún una de las regiones más pobladas. La inmigración comenzaba a imponerse, puesto que en ese total había 211.000 extranjeros. Por entonces, Buenos Aires tenía 177.000 habitantes, mientras que Córdoba y Santa Fé, las ciudades que le seguían directamente en el número de habitantes, unos $20.000^{19}$. En 1881, la recientemente incorporada Capital de la nación tenía ya 289.925 habitantes y sólo en la provincia de Buenos Aires la población alcanzaba a 526.584 personas $^{20}$.

Volviendo a las epidemias, las razones del aumento de víctimas mortales eran varias: el incremento demográfico de la Capital porteña y de la Provincia de Buenos Aires, las consecuencias sociales de la urbanización acelerada y por supuesto, la imposibilidad de vacunar a toda la población. Se desconocía la situación epidémica del resto del país, aunque cada tanto aparecía en la prensa nacional y médica información sobre brotes de viruela en las ciudades de Cuyo (Mendoza) y del Noroeste argentino (Tucumán).

\section{Una ley ineludible pero resistida}

La necesidad de legislar la obligatoriedad de la vacunación surgió paralelamente a la detección del aumento de víctimas mortales. Pero no fue una medida aceptada de manera fácil: la resistencia se observa tanto en la población como en las dificultades para distribuirla. La oposición puede sistematizarse en dos grandes grupos: por un lado, en los sectores populares, partícipes de una cosmovisión fatalista y también temerosos de aceptar un remedio que a la vez, producía la enfermedad (si bien atenuada); y por otro lado, en los profesionales y funcionarios, renuentes a poner en funcionamiento una medida reputada poco eficaz, engorrosa y costosa. Debemos aclarar que en este momento la discusión no sale de los límites de la Provincia de Buenos Aires; si bien era lógico plantear más allá de la provincia medidas semejantes, la imposibilidad política de hacerlo impidió generar un proyecto de alcance nacional.
La negativa de la población a aceptar libremente la medida iba unida a la dificultad de aislar a los afectados y prevenir el contagio, papel en el cual estaban directamente imbricadas las creencias y costumbres de los sectores populares y de la Iglesia. El relato del médico Lucio Meléndez sobre la primera epidemia de consideración, sucedida en 1871, expresaba éstas y otras dificultades, poniendo como principales causantes no sólo a la fatalidad sino a la ignorancia y la desidia. La "mortífera enfermedad" se dispersó desde los pueblos del Norte de la campaña bonaerense (San Pedro, Junín, Baradero, Zárate), por la costa del Río Paraná, hasta la provincia de Santa Fé y llegó al puerto de Rosario. El médico, indignado, resaltaba en exaltadas páginas a sus colegas que jamás había encontrado mayor resistencia en las personas adultas y en los padres de los niños para prestarse a recibir los beneficios de este verdadero e incontrovertible descubrimiento de Jenner. Unos aducían como causa, para prestarse a esta pequeña operación, la duda que si la viruela que se les trataba de inocular sería de buena calidad, otros la inutilidad del profiláctico, pues que si estaba previsto por Dios que sus hijos debian ser atacados por el flagelo y morir quizás por sus consecuencias, todo sería inútil. ;Triste desengaño para el comisionado que en nombre de la ciencia y de la experiencia de tantos siglos recibía un no, fundado en un raciocinio tan ilógico, como basado en ideas de tanto salvagismo [sic] e ignorancia ${ }^{21}$ !

A esta situación se le agregaba la imposibilidad de aislar a los enfermos y muertos. El virus se dispersaba a partir del hacinamiento de las viviendas, en los lazaretos y hospitales, como luego confirmaría José Penna en la ciudad de Buenos Aires, y también en ocasión de ceremonias religiosas. Meléndez expresaba que el contagio dependía de las perniciosas costumbres populares, ya que los cadáveres no eran inhumados sino después de prolongadas festividades. Los "velorios de angelitos" eran usuales sobre todo en el caso de la muerte de niños pequeños, y culminados esos rituales recrudecía el ciclo epidémico.

También eran responsables las autoridades eclesiásticas que aceptaban esos prolongados velatorios y los entierros en las parroquias y no suspendían confirmaciones ni bautismos aún cuando hubiese enfermos recientes con costras y cicatrices de la viruela aún frescas, con la ropa quizás que usaron en la enfermedad o que por lo menos se encontraba impregnada del virus contagioso ${ }^{22}$. Los obispos y sacerdotes no acataban directamente la autoridad médica que imponía el aislamiento e, indirectamente, promovían entre los fieles la acep- 
tación de las epidemias como castigo a sus pecados. La vacunación, proyecto científico y laico, venía así a competir con la Iglesia por el cuidado de los cuerpos; daba la posibilidad de escapar a la condena, prolongar la vida y poner en entredicho la dependencia de la religión.

La obligatoriedad terminaría, según la visión de los expertos, con la oposición soterrada y abierta a recibir el virus atenuado. Esta élite médica medía al resto de la sociedad bajo el parámetro de la ignorancia y/o la superstición; luchar contra una y otra era imposible sin el apoyo de las autoridades estatales o del sistema educativo; el primero no necesariamente de acuerdo con esta regulación y el segundo inexistente. Veamos seguidamente las argumentaciones contrarias a la obligatoriedad en virtud de las dificultades administrativas.

El primer proyecto en este sentido surgió, como era previsible, luego de la epidemia de 1871 y fue presentado a la Legislatura por el Consejo de HigiePe pública un año después pero no logró la aprobación ${ }^{23}$. Esto demuestra la tibia influencia del principal órgano sanitario, situación que intentó modificar la Asociación Médica Bonaerense, corporación de facultativos formada recientemente en el escenario porteño ${ }^{24}$.

En 1878, el médico vacunador Justo Meza presentó un proyecto a la Asociación, refrendado por Lucio Meléndez, Emilio Coni y Juan Díaz ${ }^{25}$. En el mismo se expresaba que la vacunación debía ser obligatoria en todo el territorio provincial y realizarse entre los primeros seis meses y el año de vida; se establecía la revacunación, la cual debía exigirse a empleados y funcionarios públicos, se proponía a las municipalidades y médicos de campaña como organismos de control y se vinculaba la medida sanitaria con la alfabetización, ya que no podría admitirse a ningún alumno en las escuelas sin acreditación de estar vacunado. Se fijaban asimismo multas para quien infringiera este código ${ }^{26}$.

La presentación fue sin embargo rechazada por otros asociados, a pesar de que se publicaba acompañada del relato escalofriante de Meléndez sobre la epidemia de 1871. La argumentación general fue que la Asociación no tenía personería para dirigirse a las Cámaras ${ }^{27}$, pero también en el proyecto se aducían razones administrativas sobre la forma de distribuir la vacuna, retrucando los argumentos anteriores sobre la resistencia. El médico Justiniano Ledesma señalaba así: "no creo que haya en nuestras poblaciones una resistencia obstinada a la vacunación, lo que solamente se observa es olvido e indolencia" ${ }^{28}$, además, dejaba entrever los riesgos que la población observaba en la vacuna en tiempos de epidemia.

Para Ledesma, el problema era el control efectivo del sistema público sobre los vacunados ya que si bien la obligación se iniciaba en el primer año de vida, recién a los siete años podría saberse si se había cumplido o no, es decir, cuando se ingresara al primer grado escolar. En ese interin, las epidemias podían atacar a la población y mucho más, a la infantil. A tales cuestiones, Meléndez había respondido expresando que los curas no administrasen el bautismo a quienes no estuviesen vacunados para lograr la protección frente a la enfermedad a recién nacidos o niños pequeños, pero Ledesma se preguntaba si sería posible descentralizar en tal medida la distribución de la vacuna y además, - irónicamente -, si los sacerdotes estarían de acuerdo con este condicionamiento.

En relación con la obligación a la revacunación - que el proyecto anterior consideraba para los empleados y funcionarios públicos - señalaba iguales reparos, porque implicaba que una persona podía estar diez o veinte años sin volver a vacunarse y recién allí se lo podría multar. Además, Ledesma se preguntaba cómo se perseguiría a los infractores, quiénes y cómo harían el seguimiento y la inspección de todo ese conjunto de personas ${ }^{29}$. En resumen, cómo instrumentar una política de regulación sin una estructura y sin controladores.

Frente a la inminencia del contagio, y en momentos críticos, se forzaba efectivamente a la población a vacunarse. Pero para ello se requería evidentemente de un "poder de policía" que los médicos porteños estaban lejos de contar. Ponían como ejemplo otras áreas del país, como la provincia de San Luis (región de Cuyo), donde el facultativo Benjamín Dupont penetró "en todas las casas y ranchos a inocular en las masas el gran profiláctico" ${ }^{30}$. En Buenos Aires, los estudios estadísticos de Emilio Coni establecían que tres cuartas partes de los niños nacidos no se vacunaban ${ }^{31}$ y José Penna señalaba que en cuarenta años (18421883 ) sólo tenían registro de 24.784 vacunados, lo cual indicaba un retroceso ya que sólo en 1805 se habían vacunado 200 personas.

El suministro del "virus vaccínico" constituía un problema anexo, ya fuera en relación a su calidad - es decir, sin contaminación de otras patologías como la sífilis o la tuberculosis -, como a su cantidad, ya que era necesario generar las placas para llegar a todos los médicos en los distintos distritos de la campaña o en los barrios de la capital porteña. El conservatorio de vacuna del Instituto Veterinario Santa Catalina en Monte 
Grande proveía del virus sobre todo al personal encargado de la vacunación en la ciudad de Buenos Aires, que eran un médico y entre cinco o seis practicantes de medicina, es decir, estudiantes avanzados y a los 80 partidos bonaerenses. Según Justo Meza, quien se negaba por entonces a utilizar vacuna humana o sea virus obtenido de costras de otros enfermos o vacunados y pasible de contaminación, la cantidad de vacunas era suficiente para abastecer a todos los que la requiriesen, incluso a los facultativos que difundían la medida entre su clientela.

Esta cuestión es interesante puesto que plantea que la vacunación era también un asunto privado y no únicamente público y por lo tanto, era preciso examinar su eficacia y vencer sucesivas resistencias que provenían de ámbitos y sujetos muy diversos. Había personas que, por haber sufrido la viruela y sobrevivido, consideraban que no era necesario vacunarse. Los médicos debían informar las dosis y repeticiones pero rara vez lo hacían; disponían del virus gratuitamente y cobraban por su colocación. Por lo tanto, esas vacunaciones no se contabilizaban para que "aumentase la estadística del año".

Además, "curanderos y medicastros", parteras y flebótomos, colocaban la vacuna ante la ausencia de médicos y practicantes, y en esos casos lo hacían según Meza siempre en forma ineficiente. Y por último, unos y otros, poco experimentados con esta práctica, no tenían en cuenta las variaciones que presentaba la inoculación ya que el individuo debía desarrollar una pústula para ser considerado verdaderamente a salvo de la enfermedad. En ocasiones, era preciso vacunar hasta siete veces para conseguirlo y luego repetir la operación al cabo de 5 años, porque tanto los cambios atmosféricos como las ropas gruesas impedían a veces el éxito de la operación ${ }^{32}$. Vacunar no era, como vamos viendo, una tarea sencilla, el experimentado Meza denunciaba incluso a médicos y practicantes que no sabían ni utilizar la lanceta y culpaban al material inoculado, cuando eran ellos mismos los responsables ${ }^{33}$.

Esta serie de cuestiones prácticas, enunciadas por quien fuera administrador de la vacuna, son útiles para interpretar también las resistencias a los proyectos de obligatoriedad: en primer lugar, la de los médicos oficiales y oficiosos, quienes vacunaban de manera privada y mantenían la clientela; en segundo lugar, la del "público", la gente del común, quien no estaba precisamente feliz con una medida que implicaba sucesivas aplicaciones de virus, dolorosas e incómodas. En última instancia, unos y otros defendían la no intro- misión estatal en cuestiones privadas y en esta aceptación liberal, el cuerpo era el cenáculo más defendido.

En 1878, como señalamos, el proyecto de vacunación obligatoria no fue aprobado; en 1879 lo volvió a presentar uno de los legisladores, Bermejo, pero la confusa situación política nacional de 1880 hizo imposible un avance en este sentido. Luego de un prolongado conflicto, se resuelve la subordinación de la provincia de Buenos Aires al poder federal, y Buenos Aires se transforma en Capital Federal. En ese momento, llega a la presidencia de la Nación Julio A. Roca e inicia un gobierno conservador que estructuró el Estado nacional durante una etapa de gran expansión económica ${ }^{34}$.

En 1882, la Asociación logró el acuerdo de la corporación médica y presentó otro proyecto para impulsar la vacunación obligatoria en la municipalidad porteña (firmado por Ramos Mejía, Coni, Parodi, Salvarezza y Pirovano) pero no se obtuvo la aprobación; tampoco para el Proyecto presentado en 1881 por Torcuato de Alvear al Congreso Nacional, ni para el de 1883, elevado por Mariano Demaría, director del Instituto Veterinario citado anteriormente. De acuerdo a Alvarez, en este proyecto Alvear expresaba la necesidad de intervenir en conventillos y vacunar masivamente, con o sin el acuerdo de sus habitantes, ya que esos sectores eran culpabilizados de distribuir la enfermedad ${ }^{35}$.

En ese momento, los higienistas se lamentaban de que los médicos del Congreso Nacional y de la Legislatura provincial porteña no prestasen atención a una cuestión de tanto interés para la salud humana y sin embargo, en aras de la expansión agrícola-ganadera, se ocupasen de la sarna de las ovejas o de problemas veterinarios similares. Penna citaba aquí las palabras irónicas de Coni, publicadas en la Revista Médico-Quirúrgica ${ }^{36}$.

Había ya profesionales que formaban parte del gobierno nacional y provincial, pero a este sector de médicos, deseosos de implementar las reformas, no les era fácil presionarlos. Entre 1870-1890, los casos más notables fueron el de Manuel Montes de Oca, quien participó en la legislatura porteña, fue diputado nacional y ministro de relaciones exteriores durante el gobierno de Avellaneda; Mauricio González Catán, legislador provincial en 1870 y nacional en 1880, partidario de Roca; Guillermo Rawson, diputado, senador y ministro del interior durante la presidencia de Mitre y Eduardo Wilde, partidario de Roca primero y después de Juárez Celman, de quien fue ministro de instrucción pública en 
1882 y ministro del interior en 1886 . Estos cuatro médicos también tuvieron una actuación destacada en la Academia y Facultad de Medicina y en el Consejo y Departamento de Higiene ${ }^{37}$. Tal situación, sin embargo, comenzaría a cambiar en los años siguientes, cuando los médicos pudieron imponer de forma más eficaz sus intenciones higiénicas a un espectro social mayor.

\section{La vacunación obligatoria y la "dictadura sanitaria"}

Luego de las Campañas militares de 1879-1881 en la Pampa y Patagonia, el Estado había logrado incorporar las tierras de mapuches, ranqueles, pehuenches y otras etnias nativas; la población superviviente fue concentrada en penales (como la Isla Martín García) y luego distribuida a particulares, al Ejército Nacional y a la Marina. La viruela se extendió a las familias indígenas y afectó por igual a niños y adultos, sin que se lograra detener la altísima mortalidad. Un facultativo de entonces, B. Sommer registró los casos y la terapéutica utilizada en el Lazareto porteño ${ }^{38}$. Para entonces, la ciudad de Buenos Aires había sufrido una serie de epidemias que profesionales, vecinos y autoridades vinculaban, entre otras cuestiones, a la introducción de indígenas sin vacunación y susceptibles a viruela confluente, aunque también podía deberse a un aumento demográfico en las áreas urbanas más desfavorecidas de la ciudad.

De acuerdo a uno de los mayores especialistas contemporáneos en el tema, José Penna, la enfermedad podía presentarse de manera grave o muy grave (viruela confluente) o bien, de una manera mucho más leve (viruela discreta). La primera afectaba sobre todo a la población nativa pero también a los argentinos no vacunados y era generalmente mortal; la segunda era común entre los vacunados y revacunados y prácticamente la única que aparecía en las epidemias en Europa, donde la inmunización era más general ${ }^{39}$.

Esta cuestión fue central para impulsar la legislación de obligatoriedad, ya que por un lado se consideraba una medida propia de países desarrollados, civilizados y modernos. Emilio Coni, en un viaje realizado como "misión sanitaria” por los países europeos, revisó la legislación de Gran Bretaña y Francia e hizo contactos en Turín para obtener muestras utilizables en el conservatorio de vacuna del citado Instituto Veterinario Santa Catalina. Por otro lado, la estadística pormenorizada de mortalidad infecciosa realizada por este higienista en los centros hospitalarios porteños dejaba a la luz que la mayoría de las víctimas eran argentinos, a pesar de alta proporción de extranjeros en la población de la ciudad: Esta desproporción se explica por la sencilla razón de que en Europa la vacunación es estrictamente obligatoria, lo que no sucede aquí, y eso que ataca menos a los extranjeros, aunque estos vivan en peores condiciones higiénicas que los naturales [...] En ninguna nación del continente europeo hace la viruela tantos estragos como entre nosotros ${ }^{40}$.

La Constitución Nacional de 1853 enfatizaba desde su preámbulo la apertura del país a la introducción de inmigrantes, situación que se enfatizó en la legislación posterior (Ley 876, aprobada en 1876). La población creció de manera ininterrumpida entre 1857 y 1914, a tasas anuales superiores al 3 \% y pasó de 1.830.214 habitantes en 1869 a 7.885.237 en 1914, de acuerdo al III Censo Nacional. Este crecimiento espectacular y único en América del Sur fue producto sobre todo del aporte de población extranjera ${ }^{41}$.

A finales del siglo XIX, la nación ingresó en el sistema capitalista mundial como productora de materias primas y receptora de capital, tecnología y mano de obra. La inmigración, y lo que de manera general se denominó contemporáneamente "el progreso argentino", estimularon también un proceso de urbanización acelerada en las principales ciudades del Litoral. Un 90\% de los extranjeros se estableció en la región pampeana y un $75 \%$ en las ciudades, preferentemente en Buenos Aires, contribuyendo a un temprano desarrollo de la industria de servicios e industria ${ }^{42}$. La gran mayoría vivía en conventillos, viviendas inadecuadas y sucias, sin servicios sanitarios de ningún tipo, en habitaciones pequeñas y sin ventilación. El contagio epidémico era, en los barrios populares, una realidad palpable, para la cual se requerían medidas urgentes.

En 1886, la legislatura porteña aprobó finalmente la vacunación obligatoria, sobre la base del proyecto presentado por E. Coni ya en 1878 , en el cual se conectaba la vida de los recién nacidos al registro estatal. En la reglamentación de 1887, la instrumentación dependía del Registro Civil, organismo creado bajo el gobierno de Julio A. Roca a partir de la Ley 1565 para la Capital Federal y los Territorios Nacionales y que en 1889 se generalizó al resto del país ${ }^{43}$. Esta institución estatal muy reciente fue imbuida de una función sanitaria esencial, bajo el signo de la intervención médica. Los registros civiles de Capital Federal, ya que la ley en principio fue sólo obligatoria para ese distrito, debían remitir cada seis meses 
una copia de los nacimientos inscriptos con el domicilio de los recién nacidos a la Dirección de Asistencia Pública, que enviaba vacunadores a los hogares y otorgaba certificados una vez cumplida su obligación. La vacuna era entonces gratuita. Además, la Dirección debía revacunar a los inmigrantes llegados al país - para lo cual se apersonaban a la llegada de los barcos en el puerto o bien, en el Hotel de Inmigrantes - y a los niños en escuelas y colegios. La Ley 1420 de 1884 había establecido la educación primaria laica y obligatoria para la Capital y Territorios Nacionales y a su vez, la legislación de 1886 planteaba que al ingresar al primer curso escolar se debería llevar un certificado de vacunación.

En 1889 se vacunó masivamente, ya que se registraron 18.349 personas, sobre todo en los conventillos que figuran en la nómina de la dirección de Asistencia Pública, así como en otros instalados con posterioridad, para lo cual se distribuyeron 42 practicantes a domicilio ${ }^{44}$. Cada uno de ellos debía presentar, una vez finalizada su tarea, un registro estadístico. Para que la vacunación fuese eficaz ya no era posible depender del Instituto Veterinario, alejado de Buenos Aires, sino fue necesario organizar una institución similar en la misma Capital.

Coni, uno de los mayores defensores de la medida, expresaba que en estos primeros momentos se dieron instrucciones pormenorizadas a casi la cincuentena de vacunadores que recorrían los domicilios más pobres para que no disminuyera la eficacia de la inoculación o se infectara con otras enfermedades. Pero esto parecía insuficiente, y se asumía la necesidad de centralizar además la medida para que un solo cuerpo homogéneo condensase la acción de la vacuna entre escolares e inmigrantes, además de actuar en las viviendas populares. Según este mismo facultativo, las resistencias opuestas en las antiguas casas de inquilinatos no han sido insuperables. No se ha llegado el caso de hacer efectivo las penas establecidas en la ordenanza, bastando la persuasión en el mayor número de los casos y excepcionalmente la presencia del inspector municipal o de un vigilante para que la oposición desaparezca por completo ${ }^{45}$.

Tal situación contrasta manifiestamente con la expresada pocos años atrás por el mismo Coni y nos permite entonces observar paralelamente a la medida sanitaria la "conversión" de la resistencia a la aceptación. Un análisis crítico del discurso también obligaría a reflexionar sobre los cambios, relacionados no tanto con la incorporación de la vacunación a la vida cotidiana sino con la imposición de vacunadores acompañados de la policía y/o inspectores. Las multas habían existido siempre pero las quejas de los funcionarios hacen pensar que pocas veces se aplicaban, en cambio, el nuevo sistema administrativo implicaba una coerción física nueva y original.

Como vemos, se incrementó el plantel de empleados (durante años fueron sólo el encargado y de 4 a 5 practicantes) y se obligó a una coordinación general entre agencias públicas de diverso orden. La reforma institucional sanitaria fue otro de los factores que incidió en este proceso. El Consejo de Higiene fue reemplazado en 1880, bajo el gobierno de Roca, por el Departamento Nacional de Higiene, quien tenía entre sus amplias funciones inspeccionar la vacuna. Muy poco tiempo después, en 1883, se creó la Administración Sanitaria y Asistencia Pública en el ámbito porteño. En 1886 y bajo una epidemia de cólera, asumió su dirección José María Ramos Mejía e impuso una "dictadura sanitaria" en toda la ciudad. La oposición a las medidas del higienista llevaron a un conflicto con el entonces intendente Torcuato de Alvear, quien determinó su alejamiento $^{46}$, pero aún así, la mención de un gobierno autoritario bajo el signo higienista es un signo de atención de las transformaciones sociales e ideológicas.

\section{Una nación sana y un proyecto nacional en los bordes del país}

Esta legislación iba unida a la denuncia obligatoria de enfermedades contagiosas que los médicos debían realizar a la policía y autoridades sanitarias y se hizo extensiva ese mismo año a la Provincia de Buenos Aires. En otras provincias, como la de Entre Ríos, Santa Fé, San Juan y Córdoba había ordenanzas municipales similares, aunque no siempre planteaban la obligatoriedad de la medida. La regulación la realizaba, en los casos provinciales, los respectivos Consejos de Higiene o las municipalidades de las capitales. Se sancionó la obligatoriedad en 1883 en Entre Ríos y en 1887 en San Juan. En el resto de las provincias mencionadas (como Tucumán, La Rioja, Santiago del Estero, Mendoza, Jujuy y otras) hay muy poca información, salvo que existía la vacunación sin la condición de obligatoriedad ${ }^{47}$.

De acuerdo a la organización federal del país, la autonomía provincial implicaba que el Departamento Nacional de Higiene no podía intervenir en cuestiones sanitarias provinciales, que dependían de los propios Consejos de Higiene. En los Territorios Nacionales, formados a partir de 1884 , 
la situación era distinta, puesto que su organización estaba directamente ligada a la autoridad central. La integración de estos espacios al resto del espacio nacional se realizó a partir de la violencia y la expoliación de la población nativa, más que a partir de pactos y alianzas con las elites locales, como sucedió en las provincias. En 1884, la ley 1.532 había delimitado nueve entidades jurídicas: Misiones, Formosa, Chaco, La Pampa, Neuquén, Río Negro, Chubut, Santa Cruz y Tierra del Fuego. A ellos se agregó, en 1900, el de Los Andes. Su particular inserción dentro del conjunto nacional determinó un status diferente del de las provincias históricas, puesto que éstas existieron antes que la Constitución Nacional, delegando sus atribuciones al gobierno federal. Los Territorios, por el contrario, eran simples divisiones administrativas o geográficas, posteriores a la sanción de la Constitución; los gobernadores eran elegidos por el poder central y dependían en todo de la administración nacional. Así, gran parte del país quedó bajo la égida del organismo nacional pero eran regiones muy particulares, con escasa población, sin transportes y donde el Estado realmente tenía todo por hacer ${ }^{48}$.

En 1892, con la llegada de Coni a la dirección de la Asistencia Pública - que asume ese mismo año un status nacional -, el proyecto higienista sube otro escalón sobre todo en la ampliación de servicios sanitarios y médicos en la Capital Federal, cuya distancia con el resto del país comienza a ser cada vez mayor. Susana Belmartino señala que entre 1890-1910 en Capital Federal hubo un aumento considerable de la atención en los hospitales públicos y privados; la población se incrementó en un $130 \%$ y la atención, el $271 \%$ en los hospitales municipales, $188 \%$ en los nacionales y $116 \%$ en los de las colectividades de inmigrantes. En 1909, había 13 establecimientos públicos con 2.214 camas y 20 sanatorios privados con 724 camas. Esta cuestión tiene relación con mejores expectativas respecto a las posibilidades técnicas, ya que la mortalidad hospitalaria en los mismos centros descendió de más del 40\% en 1855 a menos del $4 \%$ en $1912^{49}$.

La situación de Buenos Aires estaba lejos de replicarse en todo el país que, salvo algunos centros urbanos del Litoral, iba muy a la zaga. De acuerdo a Domingo Cabred, había en 1918 un total de 197 hospitales y 22.756 camas, cuando la población superaba los 8 millones de habitantes. El promedio era de 2,88 camas cada mil personas, pero las diferencias eran notorias entre Buenos Aires (3,19 por mil), las provincias del Norte (2,62 por mil) y los Territorios Nacionales $(0,93$ por mil $)^{50}$. Sobre la morbilidad y mortalidad la información era muy escasa cuando no inexistente, aunque al ser reducida la urbanización existía la esperanza de que las epidemias no tuvieran efectos catastróficos ${ }^{51}$.

La intención de medicalizar a esta población partió de una generación de técnicos aunados en un proyecto sanitario autoritario que a principios del siglo toma las riendas de las principales agencias nacionales. Los directores del Departamento Nacional de Higiene José María Ramos Mejía (1891-1900), Carlos Malbrán (1904-1910) y José Penna (1910-1916) intentaron ampliar la ingerencia estatal, - con éxito limitado -, a todo el ámbito nacional, a partir de la Ley de defensa sanitaria que preveía la intervención federal en las provincias en caso de epidemias, y la Ley $n^{0}$ 4202 de vacunación y revacunación obligatoria, sancionada en 1903, un año después.

Entre 1904 y 1910, el Departamento desplegó una intensa actividad en el interior argentino en relación con esta práctica, que implicó el traslado de personal técnico y de medicación en regiones que carecían de caminos, médicos e instituciones sanitarias. En ese período, se vacunó a 48.368 personas en los Territorios Nacionales, casi la mitad de la población total de esas regiones y aunque las dificultades en la administración de la medida no cesaron, gracias a una fuerte dosis de voluntarismo e implicancia de los empleados estatales - no sólo sanitarios, sino de la policía y educación - la medida llegó a aceptarse. La resistencia, apuntada por los médicos de los Territorios y por los mismos vacunadores tampoco cesó pero en general, la práctica se hizo cotidiana y habitual. Las protestas eran aisladas y provenían de personas de bajos recursos y analfabetas; no hemos encontrado situaciones análogas presentadas por corporaciones, grupos o individuos con cierta influencia política o ideológica.

En todo el país, Coni certificaba la vacunación de tres millones de personas en la primera década del siglo XX. Las placas se obtenían en el Instituto de Bactereología y seroterapia, del cual dependía el Conservatorio Nacional de Vacuna; los empleados no eran numerosos (se señalaba a unas seis personas) y estaban obligados a desplazarse a diferentes puntos del país casi mensualmente. Así, se señalaba triunfalmente un brusco descenso de la mortalidad por viruela en la Capital Federal a partir de 1912 por la generalización de la inmunidad y en el resto del territorio argentino se esperaban resultados similares cuando se completase la vacunación y revacunación de la totalidad de la población ${ }^{52}$. 
El proyecto higienista autoritario de finales del siglo XIX para sanear los conventillos y extirpar las enfermedades infecciosas continuaba en los ranchos y villorrios del interior, aunque aquí no iba a depender de la inscripción en los Registros Civiles sino de la movilidad de los funcionarios. Es preciso aclarar que en este período muy pocas localidades tenían oficinas de Registro Civil y funcionaban en su reemplazo registros volantes; por lo tanto, la dispersión de la vacuna se hizo a través de los centros sanitarios existentes en cada Territorio y en 1913, en las Asistencias Públicas que se fundaron en la mayoría de las capitales territorianas.

Por lo tanto, la propuesta ambiciosa de eliminar la viruela en todos los distritos nacionales implicaba amplificar los éxitos sanitarios de la Capital porteña, demostrando la posibilidad real de la inserción del país al concierto de las naciones modernas.

\section{Epílogo}

Las últimas epidemias de viruela que registraron un número importante de víctimas mortales se produjeron en 1945 y llevaron a sospechar que se hubiese abandonado la vacunación masiva, con altibajos entre los años treinta y cuarenta ${ }^{53}$. Hacia 1960, un análisis de casos sospechosos dio positivo en sólo 21 de las 149 muestras ${ }^{54}$. La legislación antivariólica de 1904 fue derogada recién en 1978, durante la última dictadura militar. En el decreto, se especificaba que la Sociedad Argentina de Pediatría aconsejaba suspender la vacunación por los riesgos que suponía en los niños, habiendo una remota posibilidad de enfermar. Las recomendaciones de la Organización Panamericana de la Salud y la Organización Mundial de la Salud también recomendaban suspender la vacunación antivariólica, sobre todo en áreas donde la viruela no era endémica ${ }^{55}$.

En el calendario de vacunación nacional obligatoria de 1985, con pocos cambios hasta el presente, se afirmaba que los problemas más frecuentes, a pesar de todos los esfuerzos, era la negativa de la población a vacunarse. La cobertura no llegaba al 75\% de la población cuando lo óptimo era que superara el 95\%. Las razones eran un "insuficiente conocimiento de los beneficios de las vacunas y escasa captación por parte de los servicios de salud" ${ }^{\prime 5}$. Como vemos, y aunque ya no se trate de viruela, los problemas que hemos planteado aquí son parte del pasado pero también del presente de la Argentina.

\section{Agradecimientos}

Este artículo es un aporte al Proyecto "Instituciones, actores y prácticas en el interior argentino (1884-1951)" (ANCyT-BID) y al Programa de Estudios en Historia Regional (UNLPam, FCH). 


\section{Referencias}

1. Penna J, Madero J. La administración sanitaria y Asistencia Pública en la ciudad de Buenos Aires. v. 2. Buenos Aires: Guilhermo Kraft; 1910.

2. Ramos Mejía JM. Prólogo. In: Penna J. Epidemiología - La viruela en la América del Sur y principalmente en la República Argentina: estadística, clínica y profilaxia. Buenos Aires: Félix Lajouane; 1885. p. VI.

3. Porter D, editor. The History of Public Health and the Modern State. Atlanta: Clio Medica; 1994. p. 5.

4. Di Liscia MS. Viruela, vacunación e indígenas en la Pampa Argentina del siglo XIX. In: Armus D, editor. Entre médicos y curanderos: cultura, historia y enfermedad en la América Latina moderna. Buenos Aires, Barcelona: Grupo Editorial Norma; 2002. p. 29-69.

5. Di Liscia MS. Robar el paraíso: indios, viruela y bautismo en Argentina (1870-1884). Quinto Sol Revista de Historia Regional 2000; 4:67-86.

6. Alvarez A. El reinado y el control de las endemias en la ciudad de Buenos Aires de fines del XIX a principios del XX. In: Alvarez A, Molinari I, Reynoso D, editores. Historias de enfermedades, salud $y$ medicina en la Argentina de los siglos XIX y XX. Mar del Plata: Universidad Nacional de Mar del Plata; 2004. p. 15-46.

7. Ramacciotti KI. Las sombras de la política sanitaria durante el peronismo: los brotes epidémicos en Buenos Aires. Asclepio. Revista de Historia de la Medicina y de la Ciencia 2006; LVIII:(2):115-138.

8. Cueto M. El regreso de las epidemias: salud y sociedad en el Perú del siglo XX. Lima: Instituto de Estudios Peruanos; 1997.

9. Moulin AM. A hipótese vacinal: por uma abordagem crítica e antropológica de um fenômeno histórico. Hist Cien Saúde - Manguinhos 2003; 10(Supl.2):499-517. p. 503 (mi traducción).

10. González HD, Floriani C. Tratado de enfermedades infecciosas. Buenos Aires: Vasquez; 1945. p. 552.

11. Lanning JT. El Real Protomedicato: la reglamentación de la profesión médica en el Imperio español. México: UNAM; 1997.

12. La Gaceta de Buenos Aires, 1810-1821, reimpresión facsimilar. Buenos Aires: Junta de Historia y Numismática Americana; 1910. t. II [1813].

13. Recopilación de leyes y decretos promulgados en Buenos Aires desde 1810 a 1835. Buenos Aires: Imprenta del Estado; 1836.

14. Di Liscia MS. Viruela, vacunación e indígenas en la Pampa Argentina del siglo XIX. In Armus D, editor. Entre médicos y curanderos: cultura, historia y enfermedad en la América Latina moderna. Buenos Aires, Barcelona: Grupo Editorial Norma; 2002. p. 29-69.

15. Muñiz FJ. Escritos científicos. Buenos Aires: La Cultura Argentina; 1916.

16. Oszlak O. La formación del estado argentino. Buenos Aires: Editorial de Belgrano; 1982.

17. Armus D. El descubrimiento de la enfermedad como problema social. In: Lobato MZ, director. Nueva Historia Argentina. t. V: El progreso, la modernización y sus límites (1880-1916). Buenos Aires: Sudamericana; 2000. p. 507-551.
18. Coni E. Contribución al estudio de la viruela en la Provincia de Buenos Aires. Memoria presentada a la Asociación Médica Bonaerense. Buenos Aires: Imprenta Pablo Coni; 1878. p. 8.

19. Lobato MZ, Suriano J. Atlas Histórico, Nueva Historia Argentina. Buenos Aires: Sudamericana; 2004. p. 257-260.

20. Penna J. Epidemiología - La viruela en la América del Sur y principalmente en la República Argentina: estadística, clínica y profilaxia. Buenos Aires: Félix Lajouane; 1885 . p. 80.

21. Meléndez L. La viruela en la campaña: causas de su propagación y de la excesiva mortalidad. Revista Médico-Quirúrgica 1878; 15:394.

22. Meléndez L. La viruela en la campaña: causas de su propagación y de la excesiva mortalidad. Revista Médico-Quirúrgica 1878; 15:396-397.

23. Meléndez L. La viruela en la campaña: causas de su propagación y de la excesiva mortalidad. Revista Médico-Quirúrgica 1878; 15:392.

24. González Leandri R. La profesión médica en Buenos Aires: 1852-1870. In: Lobato MZ, editor. Política, médicos y enfermedades: lecturas de historia de la salud en Argentina. Buenos Aires: Biblos; 1996. p. 21-53.

25. González Leandri R. Curar, persuadir, gobernar: la construcción histórica de la profesión médica en Buenos Aires, 1852-1886. Madrid: CSIC; 1999.

26. La vacunación obligatoria. Revista Médico Quirúrgica 1878 ; 15:392-293.

27. Coni E. La viruela en Buenos Aires: medidas adoptadas contra su propagación. Revista Médico Quirúrgica $1883 ; 20: 10$.

28. Ledesma JA. Consideraciones sugeridas con motivo a los proyectos de vacunación obligatoria. Revista Médico Quirúrgica 1878; 15:404.

29. Ledesma JA. Consideraciones sugeridas con motivo a los proyectos de vacunación obligatoria. Revista Médico Quirúrgica; 1878; 15:403.

30. Coni E. Contribución al estudio de la viruela en la Provincia de Buenos Aires. Memoria presentada a la Asociación Médica Bonaerense. Buenos Aires: Imprenta Pablo E. Coni; 1878. p. 6.

31. Coni E. Contribución al estudio de la viruela en la Provincia de Buenos Aires. Memoria presentada a la Asociación Médica Bonaerense. Buenos Aires: Imprenta Pablo E. Coni; 1878. p. 15.

32. Coni E. Apuntes sobre el movimiento de la población en la ciudad de Buenos Aires durante el año 1878. Buenos Aires: Imprenta Pablo E. Coni; 1879.

33. Coni E. Movimiento de la población en la ciudad de Buenos Aires durante el año 1880. Buenos Aires: Imprenta P. Coni; 1881.

34. Botana N. El orden conservador: la política argentina entre 1880 y 1916. Buenos Aires: Sudamericana; 1985.

35. Alvarez A. El reinado y el control de las endemias en la ciudad de Buenos Aires de fines del XIX a principios del XX. In: Alvarez A, Molinari I, Reynoso D, editores. Historias de enfermedades, salud $y$ medicina en la Argentina de los siglos XIX y XX. Mar del Plata: Universidad Nacional de Mar del Plata; 2004. p. 26. 
36. Penna J. Epidemiología - La viruela en la América del Sur y principalmente en la República Argentina: estadística, clínica y profilaxia. Buenos Aires: Félix Lajouane; 1885.

37. Di Liscia MS. Saberes, terapias y prácticas indigenas, populares y científicas en Argentina (1750-1910). Madrid: Colección Biblioteca de Historia de América, CSIC; 2002. Cap. VIII.

38. Sommer B. Contribución al estudio de una epidemia de viruela. Buenos Aires: Imprenta La Pampa; 1884

39. Penna J. Epidemiología - La viruela en la América del Sur y principalmente en la República Argentina: estadística, clínica y profilaxia. Buenos Aires: Félix Lajouane; 1885. p. 191.

40. Coni E. Contribución al estudio de la viruela en la Provincia de Buenos Aires. Memoria presentada a la Asociación Médica Bonaerense. Buenos Aires: Imprenta Pablo E. Coni; 1878. p. 16.

41. Otero H. Estadística y nación: una historia conceptual del pensamiento censal en la Argentina moderna, 1869-1914. Buenos Aires: Prometeo Libros; 2006. p. 121-133.

42. Meichtry N. Emergencia y mutaciones del sistema urbano. In: Torrado S, compilador. Población y bienestar en la Argentina del Primero al Segundo Centenario: una historia social del siglo XX. Buenos Aires: Ehasa; 2007. p. 61

43. Anales de Legislación Argentina, t. I, II y III. Buenos Aires: [s.n.]; 1954.

44. Coni E. Código de higiene y medicina legal de la República Argentina. t. I. Buenos Aires: Librería Etchepareborda; 1891. p. 647-648.

45. Coni E. Código de higiene y medicina legal de la República Argentina. Buenos Aires: Librería Etchepareborda; 1891. t. I. p. 648

46. Penna J, Madero P. La administración sanitaria y Asistencia Pública en la ciudad de Buenos Aires. Buenos Aires: Kraft; 1910. t. II.

47. Coni E. Código de higiene y medicina legal de la República Argentina. Buenos Aires: Librería Etchepareborda; 1891. t. II. p. 122.
48. Di Liscia MS. Imaginarios y derroteros de la salud en el interior argentino. Los Territorios Nacionales (fines del XIX y principios del XX). Entrepasados. Revista de Historia 2008; XVIII(33):49-69.

49. Belmartino S. La atención médica argentina en el siglo XX: instituciones y procesos. Buenos Aires: Siglo XXI Editores Argentina; 2005. p. 28.

50. Cabred D. Discursos pronunciados con motivo de la colocación de la piedra fundamental de los asilos y hospitales regionales en la República Argentina (Ley 4953). Buenos Aires: Talleres Gráficos J. Weiss y Preusche; 1918. p. 40.

51. Penna J, Restagnio A. Atlas sanitario argentino. Buenos Aires: Ministerio del Interior; 1916. p. 67.

52. Coni E. La viruela en Buenos Aires: extinción de la mortalidad. La Semana Médica 1917; XXIV(49):629.

53. González HD, Floriani C. Tratado de enfermedades infecciosas. Buenos Aires: Vasquez; 1945. p. 552.

54. Noble J, Salles Gomes LF, Rodrigues BA, Bica AN El diagnóstico de la viruela por medios de laboratorio en Las Americas. Boletín de la OPS 1969; junio:531-536.

55. Buenos Aires. Ley no 22109, de 22 de noviembre de 1978, Sanción: 22/11/1979; Promulgación: 22/11/ 1979. Poder Ejecutivo Nacional. Boletín Oficial 1979; 30 nov. Disponible en: http//leg.msal.gov.ar.

56. Buenos Aires. Normas de vacunación. Buenos Aires: Ministerio de Salud y Acción Social; 1985. p. 74.

Artigo apresentado em 22/4/2010

Aprovado em 27/5/2010

Versão final apresentada em 3/6/2010 